This is the accepted manuscript (post-print version) of the article. As regards to content, the post-print version is identical to the final published version, but there may be differences in typography, layout, and copyediting. Please cite the published version:

Lasse Suonperä Liebst, Peter Ejbye-Ernst, Richard Philpot, Marie Bruvik Heinskou, Jakob Demant, Kasper Lykke Dausel \& Marie Rosenkrantz Lindegaard (2019): Intervention or Involvement: A Video Observational Analysis of Bouncers in Aggressive Encounters, Deviant Behavior, DOI: 10.1080/01639625.2019.1619421

\title{
Intervention or Involvement: A Video Observational Analysis of Bouncers in
}

\section{Aggressive Encounters}

Lasse Suonperä Liebst ${ }^{1 \dagger} *$, Peter Ejbye-Ernst ${ }^{123 \dagger}$, Richard Philpot ${ }^{4}$, Marie Bruvik Heinskou $^{5}$, Jakob Demant ${ }^{1}$, Kasper Lykke Dausel ${ }^{1}$, Marie Rosenkrantz Lindegaard ${ }^{12}$

${ }^{1}$ Department of Sociology, University of Copenhagen, Øster Farimagsgade 5A, Bld. 16, Copenhagen K, Denmark

2 The Netherlands Institute for the Study of Crime and Law Enforcement (NSCR), P.O. Box 71304, 1008 BH Amsterdam, The Netherlands

${ }^{3}$ Vrije Universiteit Amsterdam, School of Business and Economics, De Boelelaan 1105, 1081 HV Amsterdam, The Netherlands

${ }^{4}$ Department of Psychology, Fylde College, Lancaster University, Lancaster, LA1 4YF, United Kingdom

${ }^{5}$ Hans Reitzels Forlag, Klareboderne 5, 1115 Copenhagen K, Denmark

$\dagger$ These authors contributed equally to this work

${ }^{*}$ Corresponding author, e-mail ls1@ soc.ku.dk, phone +45-3532-3291

Abstract

Little is known about how bouncer-patron interactions may influence a bouncer's use of physical aggression. To address this gap, we offer a micro-interactional analysis examining real-life aggressive bouncer behavior captured by venue surveillance 
cameras. Quantitative results show that bouncer physical aggression is associated with interactions where bouncers are directly involved as a conflict party, compared to situations where they solely intervene as a third-party. Further, a qualitative analysis of emotional cues identifies anger as a plausible mechanism underpinning bouncer aggression. We consider the implications of these findings for night-time economy violence prevention strategies and discuss the relevance of video data for barroom research

Keywords: bouncers; aggression; violence; micro-interaction; CCTV; videobased observation; night-time economy

\section{Introduction}

Night-time economy drinking zones provide spaces for lively social interaction, areas for recreational entertainment, as well as economic benefits for local businesses and the government (Pooley, Hadfield, and Houghton 2017). These zones, however, are also hot spots of violent crime (Hadfield, Lister, and Traynor 2009) facilitated by the wide accesibility of alcohol, the crowding of people, and a culture endorsing aggression (Graham and Wells 2003; Rossow and Norström 2011; Townsley and Grimshaw 2013).

Despite the increased use of targeted policing strategies, it has proved difficult to stem violent crime in the night-time economy (Braga, Papachristos and Hureau 2014). This may be explained, in part, by the wide discrepancy between the large and growing number of individuals who venture into the night-time economy and the relatively small number of police officers available in this setting (Levine et al. 2012). For example, Hobbs et al. (2005) report that within the city of Manchester, UK, more than 100,000 people frequent the night-time economy each weekend, with only approximately 40 police officers available to police these numbers. Given this, much of the policing is handled by commercial security firms; in the case of Manchester, approximately 1,000 bouncers overseeing bars and clubs. This skewed division of labor between the police and bouncers raises an institutional question of whether the state, de facto, is upholding the "monopoly of the legitimate use of physical force" (Weber 1978:54) in the night-time economy (see Ellickson 1994), as well as the practical question of how the bouncers manage their coercive actions. 
Such questions call for research on the role of bouncers in the night-time economy. A line of studies has identified bouncers as a situational predictor of aggression in bars (Roberts 2009), alongside environmental features such as high levels of intoxication (Homel, Tomsen, and Thommeny 1992), loud music (Hughes et al. 2011), and the cleanliness of the venue (Graham et al. 2006a). A correlation between bouncer presence and barroom violence, however, is unable to establish causal claimsthat is, are the bouncers hired because of the presence of aggression, or is it the presence of the bouncers that stimulates the aggression?

An alternative line of research has extended investigations beyond environmental risk factors towards assessments of bouncer aggression as enactments of social identities and cultural practices (Roberts 2009). Several ethnographic studies thus ascribe bouncer aggression to hyper-masculine identities and working-class culture (DeMichele and Tewksbury 2004; Hobbs et al. 2002, Monaghan 2002; Winlow et al. 2001). In addition to this, studies suggest that such aggressive behavior is a culturaleconomic feature of the bouncer profession: To work as a bouncer is inherently aggressive because conflict negotiation and the potential use of physical force are the services for which bouncers are employed (Hobbs et al. 2002; Lister 2002; Tutenges et al. 2015).

One aspect that has received little attention in the literature is the actual behavior of bouncers and the face-to-face interaction processes that may shape their use of aggression and violence. Graham and colleagues (2005:756) highlight that "very little research focuses explicitly on the behavior of bar staff and how their behavior escalates or deescalates barroom aggression.” As such, they call for more systematic research into interactional violent processes, with the prospect of developing a general typology of barroom aggression (Graham and Wells 2001). This call for research reflects a broader limitation of the scientific study of violent behavior, namely that the social sciences "have hardly begun to understand violence itself. That is, we have largely ignored the intrinsic aspects of violent processes" (Schinkel 2004:6). Specifically, while the literature widely attributes violence to individual-level properties (e.g., low self-control; Gottfredson and Hirschi 1990), it is important to recognize that even the most violently predisposed individuals only act aggressively in very specific situations (Collins 2008). 
In one of the few observational studies examining bouncer-patron aggressive interactions, Graham and Homel (2012:150) propose that "aggression that arises from rule enforcement is between patrons and staff, while interventions in patron conflicts involve aggression between patrons with staff intervening as third-parties." That is to say, the physical aggression of bouncers is associated with interactions in which they become involved as a direct conflict party. The evidence supporting this distinction is tentative, however, given that the authors only provide descriptive statistics suggesting that rule-enforcing bouncers are slightly more likely to be aggressive, compared to interactions where the bouncers intervene as a third-party. In our view, however, this interactional distinction between third-party intervention and direct involvement offers a promising framework that may explain when bouncers harm the patrons they are employed serve.

The purpose of the current paper is to validate whether bouncers are indeed more likely to use violence in interactions where they are directly involved as a conflict party, compared to interactions where they remain in a third-party intervener role. This proposition resonates with Simmel's (1950) view that "dyadic" and "triadic" interaction patterns generate different social outcomes (see also Black and Baumgartner 1983). More specifically, a third-party intervening into a conflict is often ascribed the role of neutral mediator, deescalating the affectively aroused conflict state: "A third mediating social element deprives conflicting claims of their affective qualities because it neutrally formulates and presents these claims to the two parties involved" (Simmel 1950:147). This insight, that the interactional structure may shape emotional dynamics and action tendencies, has been further developed by Kemper $(1978 ; 1991)$. He suggests that emotions arise as power-status outcomes of social relations - with status loss instigating anger, which, in turn, may lead to physical aggression. Following this argument, we expect that bouncers will use physical aggression disproportionally more in cases of dyadic involvement, because the status and authority challenges inherent in such interactions may incite anger.

To date, the scarcity of interactional research of bouncer violence relates to methodological limitations of the ethnographic and observational techniques commonly employed. When interactional dynamics are observed on-site in real-time, it is difficult to capture the sequential micro-details of the interaction (Collins 2008; Morrison et al. 
2016). This limitation is noted in the bouncer literature (Graham et al. 2005), leading some scholars to advocate video-based observation as a more reliable method for analyzing real-life conflict interactions (Collins 2008; Levine, Taylor, and Best 2011; Lindegaard and Bernasco 2018). Videos allow researchers to view interaction sequences in slow motion, numerous times, and to compare their observations across researchers (Nassauer and Legewie 2018; Philpot, Liebst, Møller, Lindegaard, and Levine, 2019). Therefore, in the current study, we systematically observe, code, and analyze video recordings of naturally occurring conflicts with bouncers in public drinking settings. To our knowledge, this is the first study to offer a video-based assessment of aggressive bouncer interactions.

\section{Methods}

Our data comprised of closed-circuit television (CCTV) footage of aggressive encounters involving bouncers, obtained from the Copenhagen Police Department (data and statistical script are available as supplementary materials at osf.io/mgfy4). Data collection began by inspecting all closed police cases of violence reported in the central police district of Copenhagen between 2010 and $2012(N=933)$. From this wider dataset, we identified 164 cases that contained video footage of the reported event. We then excluded clips that did not conform to the following two inclusion criteria: the clip shows face-to-face interactions between bouncers and bar patrons; and the footage has a technical quality that allows for systematic behavioral coding (see Nassauer and Legewie 2018). The final sample comprised of 28 cases. Data was coded by two student assistants in accordance with a detailed behavioral coding framework (see Eibl-Eibesfeldt 1989; Jones et al. 2016). To evaluate the reliability of the behavioral codes, the two raters independently coded all videos. We calculated Cohen's Kappa coefficients to assess interrater agreement (Cohen 1960). Agreements were above the threshold of .61 indicating good reliability (Altman 1991).

Measures. Bouncer physical aggression was measured as a binary variable where $1=$ a bouncer in the situation performs at least one physically aggressive act, and $0=$ none of the bouncers present use physical aggression. Bouncer physical aggression included hits, kicks, slaps, excessively forceful pushes or grapples, as well as the damage of patron property (e.g., destruction of a patron's phone). Note that this 
definition does not include physical force that is proportionate to the situation at hand and that allows the bouncer to perform their occupational, placatory role (e.g., using appropriate physical force to eject an unruly patron or to pacify them).

The interaction type was captured as a binary variable where $1=$ one or several bouncers are directly involved in a conflict with one or more patrons (dyadic involvement), and $0=$ the bouncer(s) only intervene in a conflict between patrons (triadic intervention). Conflict between patron(s) and bouncer(s) was identified from visual cues of a quarrel (e.g., aggressive gesturing, patron use of physical force) or from status challenges in which the patron undermines the rules upheld by the bouncer (e.g., sneaking behind the bouncer after having been refused entry). Situations where a bouncer initially intervened as a third-party and subsequently became a main conflict party were defined as dyadic involvement cases. In situations where bouncers performed physical aggression, the interaction type was measured immediately prior to any such act. This was done to avoid a simultaneity bias whereby the interaction type is defined by the succeeding physical aggressive action.

Following Simmel (1950), and Kemper's (1978) subsequent microinteractional theory of emotions, we expect that anger is the emotional mechanism that links status challenges in the dyadic interactions with aggressive reactions. To examine this proposition, we conducted a qualitative visual microanalysis of the violent cases, in order to identify bodily cues of anger. A commonly applied technique suggests that basic emotions (e.g., anger, fear) may be inferred from innate facial expressions (Ekman and Friesen 1975). CCTV footage, however, rarely has a resolution that allows identification of these facial micro-expressions. This visual shortcoming also applies to the current video data.

Fortunately for the purpose of our research interest, recent evidence suggests that several human emotions are also expressed in whole-body postures (de Gelder 2009; Tracy and Matsumoto 2008), and these more coarse-grained emotional cues can be identified in CCTV footage. Specifically, Dael and colleagues (2012) show that hot anger is perceived to have a distinct expression profile, characterized by high rates of communicative and emphasizing gestures, combined with forward body inclination. Regarding the link between hot anger and physical aggression, they suggest that the "action tendency to attack, also typically associated to hot anger, seems to be 
represented in the forward directed movement of the trunk or body" (Dael, Mortillaro, and Scherer 2012:13). Following these methodological suggestions, prior to the use of violence, we assessed each bouncer's whole-body postures to identify cues of (hot) anger.

\section{Results}

Across the interaction types, one out of four cases contained physical bouncer aggression. Physical aggression occurred in eight out of 11 dyadic involvement encounters $(72.73 \%)$, while in zero out of $17(0.0 \%)$ encounters that remained triadic interventions (see Table 1). A two-tailed Fischer's exact test, suitable for small sample sizes (Agresti 2002), found the association between interaction type and physical aggression to be statistically significant ( $p<.001$, Cramer's $V=0.79$ ), with a large effect size (Coolican 2017).

\section{Table 1}

Association between the bouncers' use of physical aggression and interaction type

\begin{tabular}{lccc}
\hline & & Triadic intervention & Dyadic involvement \\
\hline \multirow{3}{*}{ Physical aggression } & $\#$ & [cell \#1] & [cell \#2] \\
& $\%$ & 0 & 8 \\
& $\%$ & {$[0.0)$} & $(72.73)$ \\
\hline \multirow{3}{*}{ No physical aggression } & $\#$ & 17 & [cell \#4] \\
& $\%$ & $(100.0)$ & 3 \\
Total & $\#$ & 17 & $(27.27)$ \\
& $\%$ & $(100)$ & 11 \\
& & & $(100)$ \\
\hline
\end{tabular}

Note. $N=28$.

Next, using a Ragin's (2000) Boolean approach tailored to small-N analyses, we assessed whether dyadic interaction was a "sufficient" or a "necessary" condition for bouncer aggression. Sufficiency may be established by examining whether all instances of dyadic interactions are followed by physical aggression - that is, a distribution in Table 1 where cell \#4 is void of cases and cell \#2 contains all cases. Data does not support that dyadic involvement is a sufficient condition for bouncer physical aggression.

Further, we examined the dyadic interaction as a necessary condition for the outcome. To this end, we compared the distribution of aggressive cases across the two 
interaction conditions: triadic intervention [cell \#1] and dyadic involvement [cell \#2]. A necessity explanation would entail that the physically aggressive cases are skewed in the direction of the dyadic involvement, with the strongest evidence showing no cases in cell \#1. This necessity pattern corresponds to the distribution of the data: all instances of bouncer physical aggression occur in the dyadic involvement condition.

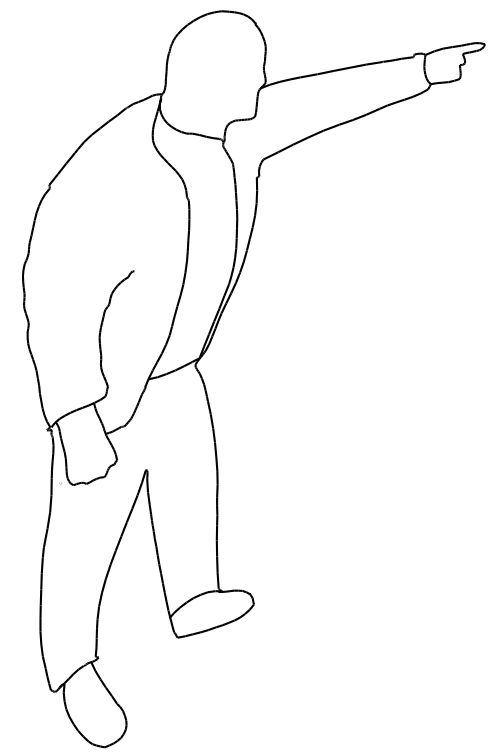

Figure 1. Postural expression of bouncer anger prior to physical aggression. Outline drawn from CCTV image.

In our theoretical framework, we expected that anger operates as an underpinning emotion linking interaction type with physically aggressive outcomes. In line with this this, we find visual evidence of anger cues in bouncer bodily postures immediately prior to physical aggression. Figure 1 illustrates one such posture - in this example, a bouncer retaliates using physical aggression towards a party of patrons who had attacked a fellow colleague. His whole-body posture shows all cues of hot anger identified by Deal and colleagues (2012): the bouncer shows emphasizing gestures combined with a forward body inclination and movement. Although similar anger bodily cues were observed across a number of the aggressive cases, we also identify other emotions and social processes. For example, in a case where a bouncer is cornered by two aggressive patrons, we do not identify cues of anger prior to the bouncer's violent response. Rather, it appears that his reaction is an attempt to defend himself and 
to fight himself out of his enclosure. This case highlights the broader point that the socio-emotional world contains more dimensions than covered in the present study (see Scheff 2011).

\section{Discussion}

Following Graham and Homel's (2012) original distinction between bouncer intervention and involvement and the theoretical perspectives of Simmel (1950) and Kemper (1978), we hypothesized that the type of bouncer-patron interaction is a key determinant of whether bouncers use physical aggression. Specifically, we expected aggression to be overrepresented in dyadic encounters in which bouncers are involved as a conflict party, compared to triadic interactions where they intervene purely as conflict moderators. The quantitative analysis confirmed this pattern, while further detailing that the dyadic involvement type of interaction is a necessary, although not a sufficient, condition for bouncer aggression. Overall, these findings are in line with the interpretation that the direct status challenge, notable in the dyadic encounters, instigates anger, which, in turn, may underpin the bouncers' aggressive reactions (see Kemper 1978). This interpretation was further supported by the qualitative visual analysis, which identified cues of anger in the bouncers' postures immediately prior to their physically aggressive actions. Taken together, these findings indicate that bouncers are not "essentially" aggressive, as commonly depicted (see Roberts 2009)—rather when violence does occur, it is conditioned on specific interactional structures.

With no triadic interventions displaying bouncer physical aggression and with over one-quarter of the dyadic conflicts also remaining peaceful, we consider the plausible mechanisms that may inhibit the bouncer's use of excessive force when interacting with patrons. First, bouncers may abstain from physically harming a patron to avoid subsequent legal and professional consequences. This cost-benefit explanation is commonly applied in criminological research to understand when perpetrators (e.g., robbers) strategically employ violence to obtain certain goals (Felson 2009; Liebst, Lindegaard, and Bernasco 2019). Second, inhibition of committing violence is in line with Collins' (2008) proposition that humans find it difficult to inflict harm on others. Specifically, humans are evolutionarily predisposed to solidarity entrainment with others, and attempts to act violently against this innate inclination arouses unpleasant 
feelings of confrontational tension/fear that keep violence at bay (see also Heinskou and Liebst 2016).

Third, the absence of bouncer aggression may be attributed to cultural expectations for emotional self-presentation in occupational settings (Goffman 1956, Hochschild 1983). Following this argument, scholars have suggested that some work situations, the bouncer profession included, require that the worker maintains an “emotional neutrality" (Ward and McMurray 2015). This may further reflect a growing "ethos of professionalism" in contemporary society (King 2013), by which the traditional masculine role is superseded by an appreciation for expertise and responsibility taking. King (2013) has recently documented this development among contemporary combat soldiers, and the bouncer profession is likely following a similar trajectory (see also Burrell and Erol 2009). The recent implementation of mandatory courses and required background checks for bouncer employment speaks in favor of this (Babor et al. 2010).

A novel contribution of the present study is the use of video data to observe and analyze naturally occurring behavior of bouncers. Similar to naturalistic on-site observations, which have found wide use within the existing bouncer literature (Geoffrion et al. 2017; Graham et al. 2006b), video-based observations allow researchers to document the violent behavior as it actually happened (Collins 2008). Yet, video-based observation has several important advantages over on-site observation, especially in overcoming issues of reliability. These problems include a high number of missing values, low interrater reliability scores, and an inability to reliably capture interactional sequences (Philpot et al. 2019).

Notwithstanding the advantages, video observation also entails methodological challenges. CCTV footage rarely includes sound and hence offers no direct information about what people are saying to one another. In the current study, we were therefore restricted to a purely physical definition of aggression - that is, in contrast to Graham et al. (2005), whose application of on-site naturalistic observations allowed them to code aggression from both physical and verbal cues. Another key limitation, shared with on-site observation, is that CCTV footage provides limited information about the social characteristics of the participating individuals or their subjective experiences and motivations. To overcome this limitation, researchers could 
triangulate video data analysis with other types of data and methods, such as ethnography, interviews, or document analysis of police-case files (see Liebst, Heinskou, and Ejbye-Ernst 2018).

Further, video data is often collected via non-probability sampling methods, questioning the generalizability of findings and estimated results (Lindegaard and Bernasco 2018; Philpot, Liebst, Møller, Lindegaard, and Levine, 2019). This is also a limitation of our data, which was collected as a convenience sample from closed police case files. As such, data is skewed towards more severe cases and may, in part, be selected on the dependent variable, i.e., reported violence committed by a bouncer (Geddes 1990). Given this potential bias, it is likely that we overestimate how frequently bouncers use violence, as those conflicts where bouncers are involved, but do not use violence, are unlikely to be police reported. Counter-balancing this potential overestimation, bouncers may sometimes use "techniques of evasion" in order to avoid legal sanctions when acting excessively aggressive (Monaghan 2002). It is therefore plausible that bouncers may destroy incriminating CCTV footage or deliberately operate in the blind angles of the cameras. However, it is our impression, after reading numerous police case files with accused and convicted bouncers, that reports of such evasion techniques are rare.

Finally, video data of crime events may be difficult to collect in large quantities, which when combined with stringent video content and quality exclusion criteria often results in small sample sizes (see e.g., Nassauer 2018; Levine et al. 2011; Philpot, Liebst, Levine, Bernasco and Lindegaard, 2019). The current study is not exempt from these challenges and, as such, the validity of our results stems from the information richness of the observations rather than from the quantitative size of the sample (Ragin 2000).

A broader and more conceptual limitation of the current study is our simple behavioral definition of physical aggression did not always overlay with the more complex behaviors observed in the footage. An illustrative example was a situation where a bouncer performed a forceful yet pacifying headlock on a bar patron, who did not fully co-operate. We did not categorize this act as physically aggressive, as it appeared proportionate in relation to the seriousness of the incident - however, this case demonstrates that the behavioral distinction between placatory and excessive force is 
often not clear-cut. Taken together, however, we should stress that the overall results are robust regardless of whether the few fuzzy cases are coded as physical aggression or not.

Previous research has identified bouncer presence as a situational risk factor for aggression in the night-time economy (Roberts 2009). However, by focusing on the presence or absence of persons, such situational approach, paradoxically, tends to default back to a person-based explanation. This tells very little about what happens within the situation itself, including, in particular, the interactional dynamics between the bouncers and patrons when aggression occurs. It should be stressed, however, that a situational analysis of interactional processes should not fetishized to the point where the person-based explanations of bouncer violence are denied (see Smith 2015; Swann and Jetten 2017; Wieviorka 2014). Such a view would neglect individual-level evidence relevant for bouncer studies, for example, findings suggesting that individuals with a more pronounced "culture of honor" tend to react more aggressively to interpersonal insults (Cohen et al. 1996; Saucier et al. 2018). Going forward, the most fruitful approach would be a synthesis of these insights into a multi-level theory of bouncer aggression and violence, acknowledging the interplay of personal properties and situational forces (see Fleeson and Noftle 2008).

Finally, our findings suggest that the bouncers' interactional routines should be included as a measure in situational crime prevention initiatives in the night-time economy. Overall, we recommend that bars and clubs organize their work routines in a manner that allows bouncers to intervene as third-party mediators, while minimizing direct conflict involvement and rule-enforcement activities (see Graham and Homel 2012). As such, bouncers should be available as a third-party response team, to intervene when a patron-to-patron conflict emerges. This is in line with previous recommendations that bouncers should avoid patrolling bars (Hauritz et al. 1998). To facilitate this, we further recommend supporting communication infrastructures where operatives from CCTV monitoring rooms and bar staff on the ground may call for bouncers when intervention is required. This would minimize bouncer presence in the barroom areas, thus reducing the opportunities for dyadic conflict encounters with patrons. 


\section{References}

Agresti, Alan. 2002. Categorical Data Analysis. New Jersey: John Wiley \& Sons. doi: $10.1002 / 0471249688$

Altman, Douglas G. 1991. Practical Statistics for Medical Research. London: Chapman \& Hall.

Babor, Thomas, Thomas F. Babor, Raul Caetano, Sally Casswell, Griffith Edwards, Joel W. Grube and Norman Giesbrecht. 2010. Alcohol. No Ordinary Commodity: Research and Public Policy. Oxford: Oxford University Press. doi: 10.1111/j.1360-0443.2010.02945.x

Black, Donald and Mary P. Baumgartner. 1983. "Toward a Theory of the Third Party." Pp. 84-114 in Empirical Theories About Courts, edited by K. O. Boyum and L. Mather. New York: Longman.

Braga, Anthony A., Andrew V. Papachristos, and David M. Hureau. 2014. "The Effects of Hot Spots Policing on Crime: An Updated Systematic Review and MetaAnalysis.” Justice Quarterly 31(4):633-63. doi: 10.1080/07418825.2012.673632

Burrell, Amy and Rosie Erol. 2009. "Tackling Violence in the Night-Time Economy on the Ground: Putting Policy into Practice in England and Wales." Crime Prevention and Community Safety 11(3):189-203. doi: 10.1057/cpcs.2009.13

Cohen, Dov, Richard E. Nisbett, Brian F. Bowdle, and Norbert Schwarz. 1996. "Insult, Aggression, and the Southern Culture of Honor: An 'Experimental Ethnography'." Journal of Personality and Social Psychology 70(5):945-59. doi: 10.1037/0022-3514.70.5.945

Cohen, Jacob. 1960. "A Coefficient of Agreement for Nominal Scales." Educational and Psychological Measurement 20(1):37-46. doi: $10.1177 / 001316446002000104$

Collins, Randall. 2008. Violence: A Micro-Sociological Theory. Princeton: Princeton University Press. doi: 10.1515/9781400831753

Coolican, Hugh. 2017. Research Methods and Statistics in Psychology. London: Psychology Press. doi: 10.4324/9780203769836

Dael, Nele, Marcello Mortillaro, and Klaus R. Scherer. 2012. "Emotion Expression in Body Action and Posture.” Emotion 12(5):1085-101. doi: 10.1037/a0025737 
de Gelder, Beatrice. 2009. "Why Bodies? Twelve Reasons for Including Bodily Expressions in Affective Neuroscience." Philosophical Transactions of the Royal Society B: Biological Sciences 364(1535):3475-84. doi: 10.1098/rstb.2009.0190

DeMichele, Matthew T. and Richard Tewksbury. 2004. "Sociological Explorations in Site-Specific Social Control: The Role of the Strip Club Bouncer." Deviant Behavior 25(6):537-58. doi: 10.1080/01639620490484068

Eibl-Eibesfeldt, Irenäus. 1989. Human Ethology. New York: Aldine de Gruyter. Ekman, P. and W V. Friesen. 1975. Unmasking the Face: A Guide to Recognizing Emotions from Facial Clues. Oxford: Prentice-Hall.

Ellickson, Robert C. 1994. Order Without Law. Cambridge: Harvard University Press. Felson, Richard B. 2009. "Violence, Crime, and Violent Crime.” International Journal of Conflict and Violence (IJCV) 3(1):23-39. doi: 10.4119/UNIBI/ijcv.46

Fleeson, William and Erik Noftle. 2008. "The End of the Person-Situation Debate: An Emerging Synthesis in the Answer to the Consistency Question." Social and Personality Psychology Compass 2(4):1667-84. doi: 10.1111/j.17519004.2008.00122.x

Geddes, Barbara. 1990. "How the Cases You Choose Affect the Answers You Get: Selection Bias in Comparative Politics." Political Analysis 2:131-50. doi: $10.1093 / \mathrm{pan} / 2.1 .131$

Geoffrion, Steve, Marcus Felson, Rémi Boivin, and Frédéric Ouellet. 2017. "Systematic Observation of Barroom Incidents in a Large Montreal Venue.” Security Journal 30(1):123-41. doi: 10.1057/sj.2014.47

Goffman, Erving. 1956. The Presentation of Self in Everyday Life. Edinburgh: University of Edinburgh Social Science Research Centre.

Gottfredson, Michael R. and Travis Hirschi. 1990. A General Theory of Crime. Stanford: Stanford University Press.

Graham, Kathryn and Samantha Wells. 2001. "Aggression among Young Adults in the Social Context of the Bar." Addiction Research \& Theory 9(3):193-219. doi: $10.3109 / 16066350109141750$ 
Graham, Kathryn and Samantha Wells. 2003. "'Somebody's gonna get their head kicked in tonight!'Aggression among young males in bars — a question of values?." British Journal of Criminology 43(3):546-566. doi: 10.1093/bjc/43.3.546

Graham, Kathryn, Sharon Bernards, D Wayne Osgood, Ross Homel and John Purcell. 2005. "Guardians and Handlers: The Role of Bar Staff in Preventing and Managing Aggression.” Addiction 100(6):755-66. doi: 10.1111/j.13600443.2005.01075.x

Graham, Kathryn, Sharon Bernards, D Wayne Osgood, and Samantha Wells. 2006a. "Bad Nights or Bad Bars? Multi-Level Analysis of Environmental Predictors of Aggression in Late-Night Large-Capacity Bars and Clubs.” Addiction 101(11):1569-80. doi: 10.1111/j.1360-0443.2006.01608.x

Graham, Kathryn, Paul F.Tremblay, Samantha Wells, Kai Pernanen, John Purcell and Jennifer Jelley. 2006b. "Harm, Intent, and the Nature of Aggressive Behavior: Measuring Naturally Occurring Aggression in Barroom Settings.” Assessment 13(3):280-96. doi: 10.1177/1073191106288180

Graham, Kathryn and Ross Homel. 2012. Raising the Bar. London: Routledge. doi: $10.4324 / 9781843925446$

Hadfield, Phil, Stuart Lister, and Peter Traynor. 2009. “'This Town's a Different Town Today': Policing and Regulating the Night-Time Economy." Criminology \& Criminal Justice 9(4):465-85. doi: 10.1177/1748895809343409

Hauritz, Marg, Ross Homel, Gillian Mcllwain, Tamara Burrows, and Michael Townsley. 1998. "Reducing Violence in Licensed Venues through Community Safety Action Projects: The Queensland Experience.” Contemporary Drug Problems 25(3):511-51. doi: 10.1177/009145099802500306

Heinskou, Marie B. and Lasse S. Liebst. 2016. “On the Elementary Neural Forms of Micro-Interactional Rituals: Integrating Autonomic Nervous System Functioning into Interaction Ritual Theory." Sociological Forum 31(2):354-76. doi: $10.1111 /$ socf.12248

Hobbs, Dick, Philip Hadfield, Stuart Lister, and Simon Winlow. 2002. “'Door Lore': The Art and Economics of Intimidation." The British Journal of Criminology 42(2):352-70. doi: 10.1093/bjc/42.2.352 
Hobbs, Dick, Philip Hadfield, Stuart Lister and Simon Winlow. 2005. "Violence and Control in the Night-Time Economy." European Journal of Crime Criminal Law and Criminal Justice 13(1):89-102. doi: 10.1163/1571817053558310

Hochschild, Arlie Russell. 1983. The Managed Heart: Commercialization of Human Feeling. Berkeley: University of California Press.

Homel, Ross, Steve Tomsen, and Jennifer Thommeny. 1992. "Public Drinking and Violence: Not Just an Alcohol Problem.” Journal of Drug Issues 22(3):679-97. doi: $10.1177 / 002204269202200315$

Hughes, Karen, Zara Quigg, Lindsay Eckley, Mark Bellis, Lisa Jones, Amador Calafat, Matej Kosir and Ninette Van Hasselt. 2011. "Environmental Factors in Drinking Venues and Alcohol-Related Harm: The Evidence Base for European Intervention." Addiction 106(s1):37-46. doi: 10.1111/j.1360-0443.2010.03316.x

Jones, Laura K, Bonnie Mowinski Jennings, Ryan M. Goelz, Kent W. Haythorn, Joel B. Zivot and Frans BM de Waal. 2016. "An Ethogram to Quantify Operating Room Behavior." Annals of Behavioral Medicine 50(4):487-96. doi: 10.1007/s12160016-9773-0

Kemper, Theodore D. 1978. A Social Interactional Theory of Emotions. New York: John Wiley \& Sons.

Kemper, Theodore D. 1991. "Predicting Emotions from Social Relations.” Social Psychology Quarterly 54(4):330-42. doi: 10.2307/2786845

King, Anthony. 2013. The Combat Soldier: Infantry Tactics and Cohesion in the Twentieth and Twenty-First Centuries. Oxford: Oxford University Press. Levine, Mark, Paul J. Taylor, and Rachel Best. 2011. “Third Parties, Violence, and Conflict Resolution: The Role of Group Size and Collective Action in the Microregulation of Violence." Psychological Science 22(3):406-12. doi: $10.1177 / 0956797611398495$

Levine, Mark, Robert Lowe, Rachel Best, and Derek Heim. 2012. “"We Police It Ourselves': Group Processes in the Escalation and Regulation of Violence in the Night-Time Economy." European Journal of Social Psychology 42(7):924-32. doi: 10.1002/ejsp.1905

Liebst, Lasse S., Marie B. Heinskou, and Peter Ejbye-Ernst. 2018. "On the Actual Risk of Bystander Intervention: A Statistical Study Based on Naturally Occurring 
Violent Emergencies.” Journal of Research in Crime and Delinquency 55(1):2750. doi: $10.1177 / 0022427817710776$

Liebst, Lasse S., Marie R. Lindegaard, and Wim Bernasco. 2019. "Dissecting the Role of Dominance in Robberies: An Analysis and Implications for Microsociology of Violence." Journal of Interpersonal Violence. doi: $10.1177 / 0886260519845713$

Lindegaard, Marie R. and Wim Bernasco. 2018. "Lessons Learned from Crime Caught on Camera." Journal of Research in Crime and Delinquency 55(1):155-86. doi: $10.1177 / 0022427817727830$

Lister, Stuart. 2002. "Violence as a Commercial Resource." The Journal of Forensic Psychiatry 13(2):245-49. doi: 10.1080/09585180210150087

Monaghan, Lee F. 2002. "Hard Men, Shop Boys and Others: Embodying Competence in a Masculinist Occupation." The Sociological Review 50(3):334-55. doi: 10.1111/1467-954X.00386

Morrison, Christopher, Juliet P. Lee, Paul J. Gruenewald and Christina Mair. 2016. "The Reliability of Naturalistic Observations of Social, Physical and Economic Environments of Bars." Addiction Research \& Theory 24(4):330-40. doi: $10.3109 / 16066359.2016 .1145674$

Nassauer, Anne. 2018. "How Robberies Succeed or Fail: Analyzing Crime Caught on CCTV." Journal of Research in Crime and Delinquency 55(1):125-154. doi: $10.1177 / 0022427817715754$

Nassauer, Anne and Nicolas Legewie. 2018. "Video Data Analysis: A Methodological Frame for a Novel Research Trend." Sociological Methods \& Research:1-40. doi: $10.1177 / 0049124118769093$

Philpot, Richard, Lasse S. Liebst, Mark Levine, Wim Bernasco and Marie Rosenkrantz Lindegaard. 2019. "Would I be Helped? Cross-national CCTV Footage Shows that Intervention is the Norm in Public Conflicts." American Psychologist.

Philpot, Richard, Lasse S. Liebst, Kim Kristian Møller, Marie Rosenkrantz Lindegaard, and Mark Levine. 2019. "Capturing Violence in the Night-time Economy: A Review of Established and Emerging Methodologies." Aggression and Violent Behavior 46:56-65. doi: 10.1016/j.avb.2019.02.004 
Pooley, Emma, Philip Hadfield and Martin Houghton. 2017. “Hackney’s Evening and Night Time Economy - a Cost Benefit Analysis." London Borough of Hackney. Roberts, James C. 2009. "Bouncers and Barroom Aggression: A Review of the Research." Aggression and Violent Behavior 14(1):59-68. doi: 10.1016/j.avb.2008.10.002

Rossow, Ingeborg and Thor Norström. 2012. "The impact of small changes in bar closing hours on violence. The Norwegian experience from 18 cities." Addiction 107(3):530-537. doi: 10.1111/j.1360-0443.2011.03643.x

Saucier, Donald A, Stuart S Miller, Amanda L Martens, Conor J O'Dea, and Tucker L Jones. 2018. “Individual Differences Explain Regional Differences in HonorRelated Outcomes." Personality and Individual Differences 124:91-97. doi: 10.1016/j.paid.2017.11.046

Scheff, Thomas J. 2011. "Social-Emotional World: Mapping a Continent." Current Sociology 59(3):347-61. doi: 10.1177/0011392111400787

Schinkel, Willem. 2004. "The Will to Violence.” Theoretical Criminology 8(1):5-31. doi: $10.1177 / 1362480604039739$

Simmel, G. 1950[1908]. "The Significance of Numbers in Social Life.” in The Sociology of Georg Simmel, edited by K. H. Wolff. Glencoe: The Free Press.

Smith, Christian. 2015. To Flourish or Destruct: A Personalist Theory of Human Goods, Motivations, Failure, and Evil. Chicago: University of Chicago Press.

Swann, William B Jr and Jolanda Jetten. 2017. "Restoring Agency to the Human Actor." Perspectives on Psychological Science 12(3):382-99. doi: $10.1177 / 1745691616679464$

Townsley, Michael and Robert Grimshaw. 2013. "The consequences of queueing: Crowding, situational features and aggression in entertainment precincts." Crime Prevention and Community Safety 15(1):23-47. doi: 10.1057/cpcs.2012.12

Tracy, Jessica L and David Matsumoto. 2008. "The Spontaneous Expression of Pride and Shame: Evidence for Biologically Innate Nonverbal Displays." Proceedings of the National Academy of Sciences 105(33):11655-60. doi: 10.1073/pnas.0802686105

Tutenges, Sébastien, Thomas F. Søgaard, Lea T. Krøll, Kim Bloomfield, and Morten Hesse. 2015. "Violent Work Environments: A Survey of Bouncers and Their 
Experiences of Violence, Stress and Other Work-Related Problems."

International Journal of Workplace Health Management 8(2):129-41. doi: 10.1108/IJWHM-06-2014-0023

Ward, Jenna and Robert McMurray. 2015. The Dark Side of Emotional Labour. London: Routledge.

Weber, Max. 1978[1921-22]. Economy and Society. Berkeley: University of California press.

Wieviorka, Michel. 2014. "The Sociological Analysis of Violence: New Perspectives." The Sociological Review 62(2_suppl):50-64. doi: 10.1111/1467-954X.12191

Winlow, Simon, Dick Hobbs, Stuart Lister, and Philip Hadfield. 2001. "Get Ready to Duck. Bouncers and the Realities of Ethnographic Research on Violent Groups.” British Journal of Criminology 41(3):536-48. doi: 10.1093/bjc/41.3.536 